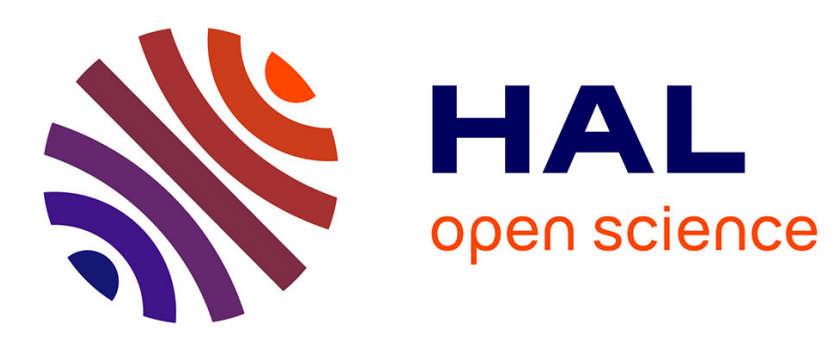

\title{
Indirect excitation of Er3+ ions in silicon nitride films prepared by reactive evaporation
}

\author{
E. Steveler, H. Rinnert, X. Devaux, M. Dossot, M. Vergnat
}

\section{To cite this version:}

E. Steveler, H. Rinnert, X. Devaux, M. Dossot, M. Vergnat. Indirect excitation of Er3+ ions in silicon nitride films prepared by reactive evaporation. Applied Physics Letters, 2010, 97 (22), pp.221902. 10.1063/1.3521279 . hal-02164303

\section{HAL Id: hal-02164303 \\ https://hal.science/hal-02164303}

Submitted on 24 Jun 2019

HAL is a multi-disciplinary open access archive for the deposit and dissemination of scientific research documents, whether they are published or not. The documents may come from teaching and research institutions in France or abroad, or from public or private research centers.
L'archive ouverte pluridisciplinaire HAL, est destinée au dépôt et à la diffusion de documents scientifiques de niveau recherche, publiés ou non, émanant des établissements d'enseignement et de recherche français ou étrangers, des laboratoires publics ou privés. 


\title{
Indirect excitation of $\mathrm{Er}^{3+}$ ions in silicon nitride films prepared by reactive evaporation
}

\author{
E. Steveler, ${ }^{1}$ H. Rinnert, ${ }^{1, a)}$ X. Devaux, ${ }^{1}$ M. Dossot, ${ }^{2}$ and M. Vergnat ${ }^{1}$ \\ ${ }^{1}$ Institut Jean Lamour, UPVM, CNRS, Nancy-University, Boulevard des Aiguillettes, B.P. 239, \\ 54506 Vandouvre-lès-Nancy Cedex, France \\ ${ }^{2}$ Laboratoire de Chimie Physique et Microbiologie pour l'Environnement, UMR 7564 CNRS—Nancy- \\ University, 405, rue de Vandouvre, 54600 Villers-lès-Nancy, France
}

(Received 22 July 2010; accepted 4 November 2010; published online 29 November 2010)

\begin{abstract}
Er-doped silicon nitride films were obtained by reactive evaporation of silicon under a flow of nitrogen ions and were annealed at temperatures up to $1300{ }^{\circ} \mathrm{C}$. Samples were studied by infrared absorption and Raman spectrometries and by transmission electron microscopy. The $1.54 \mu \mathrm{m}$ Er-related photoluminescence (PL) was studied in relation with the structure with pump excitation at 488 and $325 \mathrm{~nm}$. Steady-state PL, PL excitation spectroscopy, and time-resolved PL were performed. The results demonstrate that $\mathrm{Er}^{3+}$ ions are indirectly excited both via silicon nanocrystals and via localized states in the silicon nitride matrix. (C) 2010 American Institute of Physics. [doi:10.1063/1.3521279]
\end{abstract}

Er-doped silicon-based materials have attracted much attention in the scientific community because of their potential use for optoelectronics. ${ }^{1}$ Indeed, $\mathrm{Er}^{3+}$ ions can emit sharp luminescence at $1.54 \mu \mathrm{m}$, which is the commonly used wavelength for optical communications. The Er sensitization has been widely studied in $\mathrm{Si}$ rich $\mathrm{SiO}_{2}$ layers. In silica containing silicon nanocrystals (Si-nc), the Er-related photoluminescence is strongly improved due to a strong energy

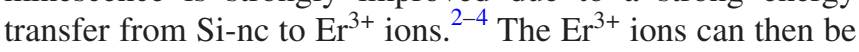
indirectly excited by $\mathrm{Si}$-nc which have an absorption cross section several orders of magnitude higher than that of direct Er excitation. While $\operatorname{SiN}_{\mathrm{x}}$ is a particularly interesting host matrix for electrically pumped light-emitting devices, the Er excitation mechanism in silicon nitride films is still not clear. Similarly to the $\mathrm{SiO}_{\mathrm{x}}$ based samples, the sensitization of $\mathrm{Er}^{3+}$ ions by $\mathrm{Si}$ nanoparticules has been reported in $\mathrm{SiN}_{\mathrm{x}}$ samples prepared by plasma enhanced chemical vapour deposition (PECVD $)^{5}$ or by magnetron sputtering. ${ }^{6}$ However, some works have also demonstrated that indirect excitation of $\mathrm{Er}^{3+}$ ions could occur via electronic states localized in the $\operatorname{SiN}_{x}$ band tail states. 7,8

In this letter, we study the Er-related PL at $1.54 \mu \mathrm{m}$ in Er-doped silicon nitride thin films prepared by an ion-beamassisted evaporation technique. The evolutions of the structure and of the PL properties with the annealing treatments are studied. It is demonstrated that the Er excitation is indirect and that Si-nc is able to improve the PL intensity. It is also shown that another indirect excitation path presumably exists in the amorphous $\operatorname{SiN}_{\mathrm{x}}$ matrix.

Silicon was evaporated from an electron beam gun with a deposition rate equal to $0.1 \mathrm{~nm} / \mathrm{s}$. The $200 \mathrm{~nm}$ thick films were deposited on silicon substrates maintained at $100{ }^{\circ} \mathrm{C}$. The nitrogen ions were provided by an electron cyclotron resonance microwave plasma source. The nitrogen flow was regulated by maintaining the total pressure in the evaporation chamber at $2 \times 10^{-5}$ Torr. The Er doping was performed from an effusion cell. Rutherford backscattering spectrometry was used to analyze the chemical content of the film.

${ }^{a)}$ Electronic mail: herve.rinnert@ijl.nancy-universite.fr.
The $\mathrm{Si}, \mathrm{N}, \mathrm{O}$, and Er atomic concentrations are equal to $47 \%$, $48 \%, 5 \%$, and $0.3 \%$, respectively. The oxygen content is due to the low density of the layer and to exposure to the air. This concentration corresponds to a 12 at. \% $\mathrm{Si}$ excess compared to the $\mathrm{Si}_{3} \mathrm{~N}_{4}$ equilibrium stoichiometry.

The Fourier transform infrared (FTIR) experiments were carried out with a spectrometer with a resolution of $2 \mathrm{~cm}^{-1}$. Raman measurements were carried out with a mutichannel spectrometer equipped with a 1800 grooves $\mathrm{mm}^{-1}$ grating. The samples were excited by the $514 \mathrm{~nm}$ line from an argon laser. Transmission electron microscopy was performed with a $200 \mathrm{keV}$ microscope. For the steady-state PL experiments, the samples were excited by a $30 \mathrm{~mW} \mathrm{He}-\mathrm{Cd}$ laser using the $325 \mathrm{~nm}$ line or by a $60 \mathrm{~mW}$ laser diode emitting at $488 \mathrm{~nm}$. For the PL excitation (PLE) experiments, the samples were excited by an optical parametric oscillator laser. The PL signal was measured by a photomultiplier tube cooled at $190 \mathrm{~K}$. For the time-resolved PL experiments, the samples were pumped by the $355 \mathrm{~nm}$ line of a frequency-tripled YAG:Nd laser. The laser pulse frequency, energy, and duration were typically equal to $10 \mathrm{~Hz}, 50 \mu \mathrm{J}$, and $20 \mathrm{~ns}$, respectively. The time response of the detection system was better than $1 \mu$ s.

Figure 1(a) shows the FTIR spectra of the films for as-deposited sample and samples annealed at 1000 and $1100{ }^{\circ} \mathrm{C}$. The spectrum shows a very intense band at around $850 \mathrm{~cm}^{-1}$, characteristic of the asymmetric stretching vibration of the $\mathrm{Si}-\mathrm{N}$ bonds. ${ }^{9}$ The spectra are not significantly modified for annealing temperatures lower than $1000{ }^{\circ} \mathrm{C}$ since only a $6 \mathrm{~cm}^{-1}$ shift occurs to higher wavenumbers. For higher annealing temperature, the peaks shift again a few $\mathrm{cm}^{-1}$ and a shoulder appears at high wavenumbers, demonstrating a modification of the $\mathrm{Si}-\mathrm{N}$ bonds, which could be correlated to the precipitation of Si-nc. ${ }^{10}$

The Raman spectrum of bulk crystalline silicon exhibits a very thin band at $520 \mathrm{~cm}^{-1}$ corresponding to the transverse optical mode. A weak contribution at around $300 \mathrm{~cm}^{-1}$ is due to longitudinal acoustic mode. In amorphous silicon, the Raman spectrum presents two broad bands at 150 and at $480 \mathrm{~cm}^{-1}$. Figure 1(b) shows Raman shifts for the different annealing temperatures. The as-deposited sample shows the 

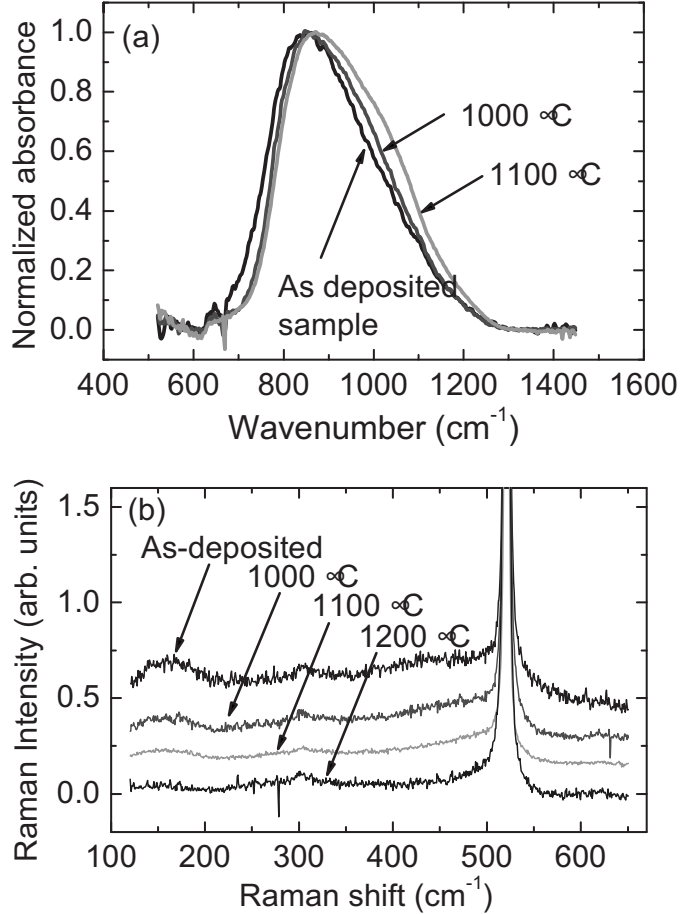

FIG. 1. (a) Infrared absorption spectra and (b) Raman shift for different annealing temperatures.

characteristic bands of pure amorphous silicon. This suggests that a part of the $\mathrm{Si}$ excess form amorphous $\mathrm{Si}$ domains in the $\mathrm{SiN}_{\mathrm{x}}$ matrix. For samples annealed at temperatures higher than $700{ }^{\circ} \mathrm{C}$, these amorphous contributions decrease with a more pronounced decrease for the samples annealed at $1100{ }^{\circ} \mathrm{C}$. For higher annealing temperatures, the amorphous peaks disappear, which corresponds to the formation of crystalline domains. ${ }^{11}$ The Raman peak due to the crystalline domains of the layer is not visible because of the strong response of the substrate.

Figure 2 shows micrographs for samples annealed at 700 and $1100{ }^{\circ} \mathrm{C}$, respectively. While the micrograph is characteristic of amorphous sample for sample annealed at $700{ }^{\circ} \mathrm{C}$, the micrograph demonstrates the existence of Si-nc for the sample annealed at $1100{ }^{\circ} \mathrm{C}$. The size distribution is wide and the average Si-nc size is equal to a few nanometers. The samples remain amorphous until an annealing temperature equal to $1000{ }^{\circ} \mathrm{C}$ and the amorphous silicon clusters crystallize for higher annealing temperatures. With a $\mathrm{Si}$ excess equal to 12 at. \%, a Si-nc mean size equal to $3.5 \mathrm{~nm}$ and a density of silicon and silicon nitride equal to 2.32 and 3.2, respectively, the density of Si-nc is estimated to $9.10^{17} \mathrm{~cm}^{-3}$.
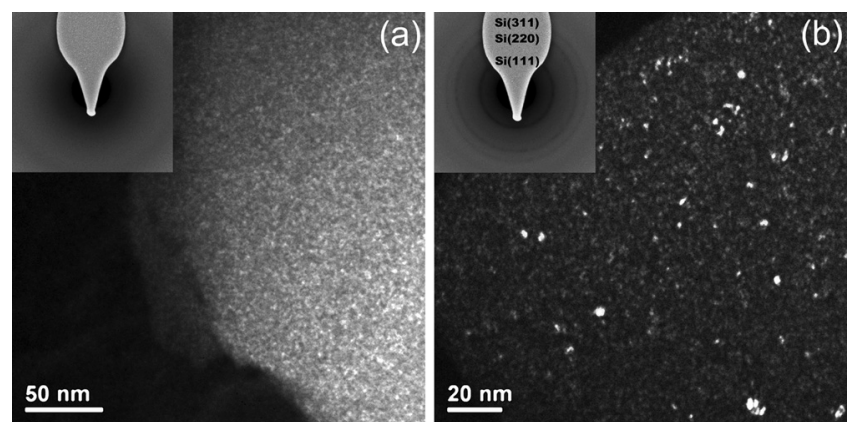

FIG. 2. Dark field views of samples annealed at (a) $700{ }^{\circ} \mathrm{C}$ (a) and at (b) $1100{ }^{\circ} \mathrm{C}$.

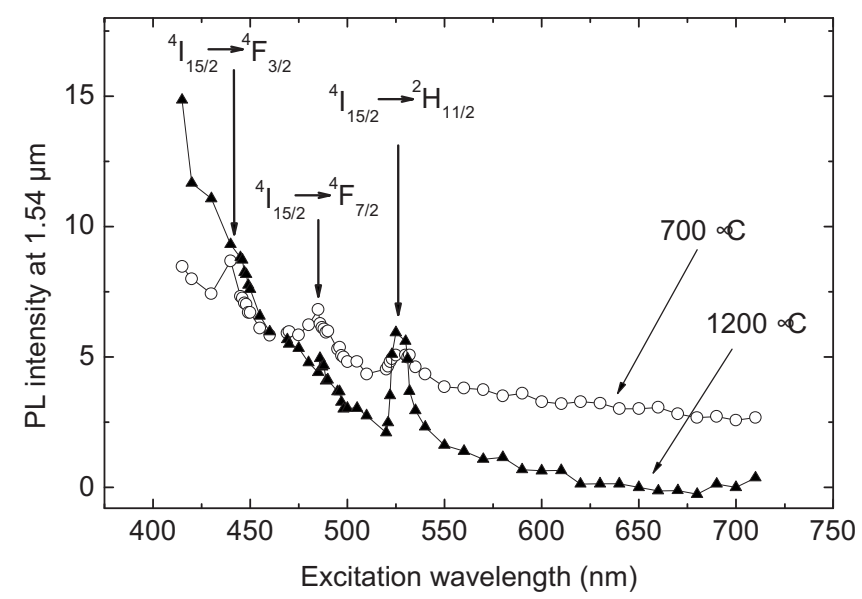

FIG. 3. Photoluminescence excitation spectra at $1.54 \mu \mathrm{m}$ for samples annealed at 700 and $1200{ }^{\circ} \mathrm{C}$.

This value probably overestimates the number of crystals because it assumes that all the $\mathrm{Si}$ excess contribute to form Si-nc.

Photoluminescence excitation spectra at $1.54 \mu \mathrm{m}$ are presented in Fig. 3 for samples annealed at 700 and $1200{ }^{\circ} \mathrm{C}$. No PL signal is obtained for the as-deposited sample. These results clearly show the characteristic direct excitation of $\mathrm{Er}^{3+}$ ions at 440, 486, and $528 \mathrm{~nm}$, corresponding to the absorption from the ground state to the excited states ${ }^{4} \mathrm{~F}_{3 / 2},{ }^{4} \mathrm{~F}_{7 / 2}$, and ${ }^{2} \mathrm{H}_{11 / 2}$, respectively. For both samples, the PLE spectra show nonresonant excitation of $\mathrm{Er}^{3+}$ ions, demonstrating an indirect excitation of the ions. This indirect process is a decreasing function of the excitation wavelength, with a more pronounced increase for the sample annealed at high temperature.

The dependence of the PL spectra with annealing temperatures is shown in Figs. 4(a) and 4(b) for excitation wavelengths equal to 325 and $488 \mathrm{~nm}$, respectively. The same photon flux was used in both cases. Samples have been measured on the same setup, with the same experimental conditions. Hence PL intensities can be compared. Whatever the excitation wavelength, no Er-related PL is measured in the as-deposited samples. An annealing at $500{ }^{\circ} \mathrm{C}$ induces in the optical activation of the $\mathrm{Er}^{3+}$ ions and the PL intensity at
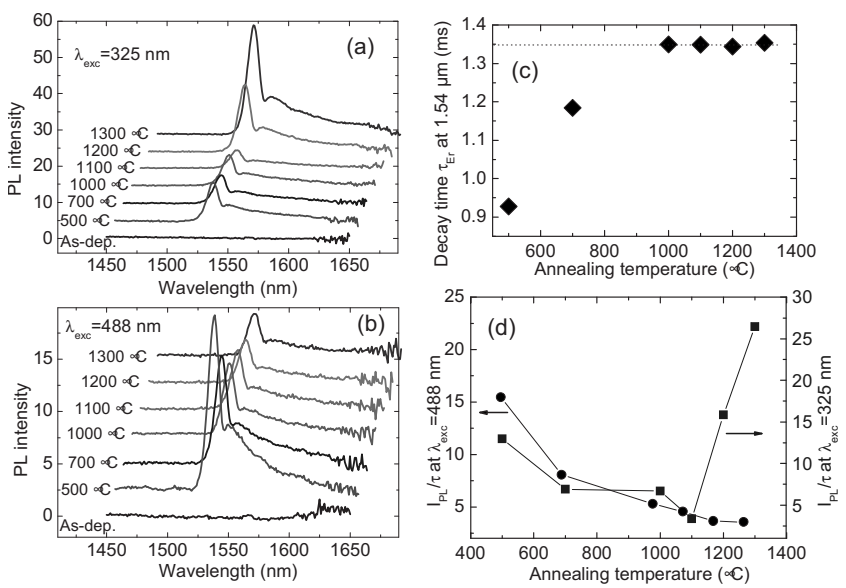

FIG. 4. Influence of the annealing temperatures on the PL spectra for excitation at (a) $325 \mathrm{~nm}$ and (b) $488 \mathrm{~nm}$. (c) Decay time for the different annealing temperatures. (d) Dependence of the $\mathrm{I}_{\mathrm{PL}} / \tau_{\mathrm{Er}}$ ratio with the annealing temperature for excitation wavelengths equal to $325 \mathrm{~nm}(\boldsymbol{\square})$ or $488 \mathrm{~nm}$ ()). 
$1.54 \mu \mathrm{m}$ is very similar for both excitation wavelengths. However, the dependence of the PL for higher annealing temperatures is strongly different. For the $325 \mathrm{~nm}$ excitation, the PL intensity is almost constant up to $1000^{\circ} \mathrm{C}$ and strongly increases for higher annealing temperatures, while, under the $488 \mathrm{~nm}$ excitation, the PL intensity is a continuously decreasing function of the annealing temperature.

The $488 \mathrm{~nm}$ wavelength is known to be resonant with the ${ }^{4} \mathrm{I}_{15 / 2} \rightarrow{ }^{4} \mathrm{~F}_{7 / 2}$ transition of $\mathrm{Er}^{3+}$ ions. As shown by the PLE experiments, $\mathrm{Er}^{3+}$ ions are not dominantly excited through the direct absorption process at this wavelength. The PL intensity decrease with annealing treatments could be explained by an increasing number of nonradiative decay channels, like the formation of Er clusters. However, the PL intensity does not follow the same evolution under the $325 \mathrm{~nm}$ excitation. Moreover, the PL decay time $\tau_{\mathrm{Er}}$, shown in Fig. 4(c), is an increasing function of the annealing temperature, which is not in agreement with the appearance of nonradiative recombination. On the contrary, the increasing decay time values suggest that some nonradiative defects have been passivated by the annealing treatment. The dependence of the PL intensity with the annealing temperature suggests that the indirect excitation process occurring at $488 \mathrm{~nm}$ is strongly reduced with annealing treatments.

Si-ncs are known to be efficient sensitizers for $\mathrm{Er}^{3+}$ ions. Modeling using coupled rate equations is commonly reported in the literature to take into account of the excitation of $\mathrm{Er}^{3+}$ ions with sensitizers. ${ }^{12,13}$ In the low pump flux regime, the $1.54 \mu \mathrm{m}$ PL intensity can be given by

$$
\mathrm{I}_{\mathrm{PL}}=\frac{\sigma_{\mathrm{Er}} \Phi \tau_{\mathrm{Er}}}{1+\sigma_{\mathrm{Er}} \Phi \tau_{\mathrm{Er}}} \mathrm{I}_{\max },
$$

where $\sigma_{\mathrm{Er}}, \tau_{\mathrm{Er}}$, and $\Phi$ are the effective excitation cross section of $\mathrm{Er}^{3+}$ ions, the PL decay time, and the pump photon flux, respectively. $I_{\max }$ is proportional to the ratio of the total number of optically activated $\mathrm{Er}^{3+}$ ions divided by the radiative decay time. Figure $4(\mathrm{~d})$ shows the $\mathrm{I}_{\mathrm{PL}} / \tau_{\mathrm{Er}}$ ratio measured for the 325 and $488 \mathrm{~nm}$ excitations for the different samples studied. This ratio is a continuously decreasing function of the annealing temperature for the $488 \mathrm{~nm}$ excitation wavelength. Interestingly, the same behavior is obtained for the $325 \mathrm{~nm}$ excitation but only for annealing temperatures up to $1000{ }^{\circ} \mathrm{C}$. For higher annealing temperatures, the ratio $\mathrm{I}_{\mathrm{PL}} / \tau_{\mathrm{Er}}$ strongly increases. These results suggest that two different indirect excitation processes occur, depending on the annealing temperature and on the excitation wavelength. As the trend change in the dependence of $\mathrm{I}_{\mathrm{PL}} / \tau_{\mathrm{Er}}$ with the annealing temperature around $1100{ }^{\circ} \mathrm{C}$ occurs simultaneously with the appearance of Si-nc, the obtained PL enhancement with the $325 \mathrm{~nm}$ excitation could be due to an energy transfer process from $\mathrm{Si}-\mathrm{nc}$ to $\mathrm{Er}^{3+}$ ions. However, the behavior is different for the $488 \mathrm{~nm}$ excitation, while Si-nc should also contribute to the energy transfer with this excitation energy. By measuring the excitation power dependence of the PL intensity at $488 \mathrm{~nm}$, the excitation cross-section has been measured for the sample annealed at $1200{ }^{\circ} \mathrm{C}$. It is equal to $2 \times 10^{-17} \mathrm{~cm}^{2}$, which is around one order of magnitude lower than that generally obtained for Er-doped $\mathrm{Si}$ rich $\mathrm{SiO}_{2}$ layers. ${ }^{12,14}$ This low value could be explained by the weak number of Si-nc that can couple with $\mathrm{Er}^{3+}$ ions. The different evolutions obtained with both excitation wavelengths can be explained by the fact that the absorption cross section of $\mathrm{Si}-\mathrm{nc}$ is a decreasing function of the wavelength. More precisely, Izeddin et al. ${ }^{14}$ have shown that the PL excitation cross-section of Si-nc is five times higher at $355 \mathrm{~nm}$ than at $488 \mathrm{~nm}$. The value at $325 \mathrm{~nm}$ can then be estimated to be around one order of magnitude higher than at $488 \mathrm{~nm}$. This result could then explain the different trends presented in Fig. 4(d). For samples annealed below $1100{ }^{\circ} \mathrm{C}$, and for an excitation at $488 \mathrm{~nm}$, the role of Si-nc on the Er-related PL is negligible compared to the matrix-mediated $\mathrm{Er}$ excitation cross section. For the excitation at $488 \mathrm{~nm}$ and for the excitation at $325 \mathrm{~nm}$ in case of samples annealed below $1100{ }^{\circ} \mathrm{C}, \mathrm{Er}^{3+}$ ions are probably excited via disorder-induced localized states in the $\mathrm{SiN}_{\mathrm{x}}$ band tails, as already mentioned in the literature. ${ }^{8}$ As previously shown in similar $\mathrm{SiN}_{\mathrm{x}}$ layers, the optical gap is an increasing function of the annealing temperature, which is explained by a decrease of the density of states in the $\mathrm{SiN}_{\mathrm{x}}$ gap. ${ }^{15}$ The annealing-induced decrease of the electronic state density in the gap could then involve in the decrease of sensitization of $\mathrm{Er}^{3+}$ ions via localized states in the gap.

In conclusion, Er related PL at $1.54 \mu \mathrm{m}$ was studied in Si-rich silicon nitride films. It is shown that an indirect energy transfer process, dependent on the structure of the films, is involved in the excitation of $\mathrm{Er}^{3+}$ ions. For low annealing temperatures, samples are amorphous and the electronic states that coupled with $\mathrm{Er}^{3+}$ ions are probably due to disorder-induced localized states in the $\mathrm{SiN}_{\mathrm{x}}$ bandgap. For annealing temperatures greater than $1100{ }^{\circ} \mathrm{C}, \mathrm{Si}$-nc could play a major role in the energy transfer process for low excitation wavelength.

${ }^{1}$ A. Polman, J. Appl. Phys. 82, 1 (1997).

${ }^{2}$ G. Franzo, D. Pacifici, V. Vinciguerra, F. Priolo, and F. Iacona, Appl. Phys. Lett. 76, 2167 (2000).

${ }^{3}$ M. Fujii, M. Yoshida, Y. Kansawa, S. Hayaski, and K. Yamamoto, Appl. Phys. Lett. 71, 1198 (1997).

${ }^{4}$ H. Rinnert, G. Wora Adeola, and M. Vergnat, J. Appl. Phys. 105, 036101 (2009).

${ }^{5}$ N. M. Park, T. Y. Kim, S. H. Kim, G. Y. Sung, K. S. Cho, J. H. Shin, B. H. Kim, S. J. Park, J. K. Lee, and M. Nastasi, Thin Solid Films 475, 231 (2005).

${ }^{6}$ L. Dal Negro, R. Li, J. Warga, and S. N. Basu, Appl. Phys. Lett. 92, 181105 (2008).

${ }^{7}$ Q. Zhao, H. Yan, M. Kumeda, and T. Shimizu, Appl. Surf. Sci. 227, 306 (2004).

${ }^{8}$ S. Yerci, R. Li, S. O. Kucheyev, T. van Burren, S. N. Basu, and L. Dal Negro, Appl. Phys. Lett. 95, 031107 (2009).

${ }^{9}$ D. V. Tsu, G. Lucovsky, and M. J. Mantini, Phys. Rev. B 33, 7069 (1986).

${ }^{10}$ G. Scardera, T. Puzzer, G. Conibeer, and M. A. Green, J. Appl. Phys. 104, 104310 (2008).

${ }^{11}$ M. Molinari, H. Rinnert, M. Vergnat, and P. Weisbecker, Mater. Sci. Eng., B 101, 186 (2003).

${ }^{12}$ D. Pacifici, G. Franzo, F. Priolo, F. Iacona, and L. Dal Negro, Phys. Rev. B 67, 245301 (2003).

${ }^{13}$ B. Garrido, C. Garcia, S. Y. Seo, P. Pellegrino, D. Navarro-Urrios, N. Daldosso, L. Pavesi, F. Gourbilleau, and R. Rizk, Phys. Rev. B 76, 245308 (2007).

${ }^{14}$ I. Izeddin, D. Timmerman, T. Gregorkiewicz, A. S. Moskelenko, A. A. Prokoviev, I. N. Yassievich, and M. Fujii, Phys. Rev. B 78, 035327 (2008).

${ }^{15}$ M. Molinari, H. Rinnert, and M. Vergnat, Appl. Phys. Lett. 77, 3499 (2000). 